We can thus remove the sulphides from the list of empiric remedies, having facts at our disposal to account for their remedial action, for I have indicated that given in a physiological dose they influence certain specific parts; and daily experience (e.g., the cases communicated by Dr. Sidney Ringer) confirms the truth of the inference that in a restorative dose they will beneficially influence the same parts when deranged, and this they do either by in some manner altering the nature and quality of the vital action of the parts or by romoving the state of combination of the elements which excited diseased action, and thus enabling the normal powers of nutrition to restore the healthy constitution; and this I consider applies not only to the sulphides but also to every other drug. Now in reference to the dose mentioned by Dr. Sidney Ringer-viz., one-tenth of a grain every two or three hours- $I$ consider the quantity quite sufficient, and this for two reasons. 1st. Because the sulphides are comparatively insoluble and slowly diffusible salts, hence require to be given in small and repeated doses to ensure their being absorbed into the system, for if a large dose be given at once it may pass through the intestinal canal before it can be changed into a condition necessary for absorption; moreover, by giving small and repeated doses we can keep the system longer under the influence of the drug. 2nd. A small dose is indicated because we wish the restorative action of a drug on a part whose functions are deranged, and not its physiological action, at least in the cases mentioned above.

I remain, Sir, your obedient servant,

Alex. G. Burness, M.B., \&c.

Green-street, Grosvenor-square, Feb. 23rd, 1874.

\section{THE CAUSE OF LATE ERRORS OF SANITARY ADMINISTRATION.}

To the Editor of The LANCET.

SIR,-While heartily approving your repeated forcible exposures of the fiasco resulting from the Public Health Act, 1872, and its administration, I must beg leave to protest against the blame being thrown wholly upon Mr. Stansfeld. It cannot surely be forgotten that the main lines of organisation of authorities and officers were laid down by the Royal Sanitary Commission, and have been all along defended pertinaciously by Sir C. B. Adderley and Mr. F. S. Powell, who, as leaders of the Commission, insisted on the independent sanitary authorisation of every small local board and town council, and every extra-urban bit of a parochial union, in the kingdom. It was these gentlemen who first proposed that each of these trumpery "authorities" should be fully empowered, and, indeed, compelled, to appoint its own health officer. Herein lies the obvious cause of the blunders which have been perpetrated.

Mr. Stansfeld, indeed, was unwise enough to adopt the main outline of their measure, although he somewhat improved it by striking out "Special Drainage Districts" from the medley of urban authorities proposed by the Sanitary Commission.

Now, Parliament having empowered and ordered each of these districts to appoint its own officers, medical or other, without any conditions as to qualification, without any means of mutual co-operation, without any power in the central authority to combine districts and their authorities, on reasonable principles, for certain purposes, what could Mr. Stansfeld's inspectors have done, had they proved the ablest administrators in the world, but say to the various local authorities within any larger area that they might fancy (no principle of action being settled by Parliament), "We advise you all to combine to make such and such arrangements"? They did this, as we know, in numerous instances, but in no one instance that $I$ am aware of did all the local authorities, within the area recommended, consent to surrender their legal right of separate appointment. One or more (sometimes many) local insulæ of administration stood out of each scheme, whether it were bad or good. The result was inevitable. It matters not whether Adderley or Stansfeld be in office under the present law, the legalised autonomy of nearly 2000 districts cannot be resisted by any central authority.

We must be just, even to our most unreasonable opponents in this matter. The error, as the joint committee of the two associations at once pointed out, was the authorisation of badly constituted authorities, and the establishment of impracticable areas of sanitary administration. To this miserable system, the origin of the present muddle, Sir C. B. Adderley is pledged, Mr. Powell is pledged. They are therefore hopeless. However desirable may be many sanitary provisions which these gentlemen propose to add to the Public Health Act (and the objects of some are very important), these provisions will have to be administered by the present incompetent and ill-constituted authorities, in the present unworkable areas. Sir Michael Hicks-Beach, Dr. Lyon Playfair, and a few others understand this question, and they would have amended the Act accordingly, had not the leaders of both parties combined to prevent amendment and to force a wretched abortion of sanitary legislation through Parliament.

Real sanitary reformers ought now to be awake. No time should be lost in clearing the public view of this vered and still misunderstood question. The demand should be-first, for the appointment of a well-informed Boundary Commission, to prepare a scheme for the adjustment of the conflicting areas of counties, boroughs, and unions, so that Parliament may be able to enforce something like conformity of arrangement and action, some rectification of conflicting jurisdictions; secondly, to bring in an amendment of the Public Health Act, empowering the central authority to correct areas and boundaries, and to combine and improve autborities; and, thirdly, to construct a proper machinery for the registration of sickness in connexion with the Registration Department, all the agents being fairly remunerated, and adequate supervision, both local and central, being secured. Then, and then only, will a proper health officer system be possible.

To throw the whole blame of the marvellous blunders that have been made in all parts of the country solely upon the central administration of an Act, which is in itself the plain source of the evils, is neither fair nor philosophical. I am, Sir, \&c.,

Cheltenham, Feb. 16th, 1874. HENRY W. RuMseY, M.D.

\section{THE TREATMENT OF TINEA TONSURANS.} To the Editor of The LanceT.

SIR,-The treatment of true parasitic ringworm of the hairy scalp is commonly so tedious that we all would gladly welcome and put to the proof any method which promised us more quick success. Hence my present letter, with which I trouble you in order that a method which on several occasions has seemed to me to be very satisfactory may be tried by others who are free from the bias of him who makes an experiment for the first time.

An eminent chemist, now dead, told me some years ago that he had been engaged by a business firm to discover the reason why their patent manures, so far from causing the crops to thrive, destroyed them. My friend believed that in a minute quantity of sulphocyanide of potassium present in the manure he had discovered a powerful poison to vegetables. The thought came into my mind that it might be worth while to try whether the same salt would kill those parasitic fungi which give us so much trouble. But it is only during the last month or two that I have put the hypothesis to the test of experiment; and the result, as I said, has been satisfactory enough to make me wish to put it to the further test of publication. My method is as follows

1. Cut the hair everywhere quite close, and keep it cropped as fast as it grows.

2. Wash the scalp with warm water and soap twice a day, and on no account let the hair get matted down on to the skin.

3. After washing and drying the head rub the following lotion well into any patches of ringworm:-Sulphocyanide of potassium, $\frac{1}{2} \mathrm{oz}$.; glycerine, $1 \mathrm{oz}$.; water, $7 \mathrm{oz}$.

4. Keep a piece of lint, soaked in the same lotion, on the scalp night and day, oil-silk upon the lint, and a calico cap over all.

I found that if the solution of sulphocyanide be stronger than $I$ have mentioned it will be very likely to set up eczema. The salt is said not to be in the least degree poisonous to man. - I am, Sir, yours truly,

Harley-street, Feb. 21th, 1874. 